\title{
Anatomical variation in the origin of left vertebral artery: A case report
}

\section{Sol arteria vertebralis orijini anatomik varyasyonu: Olgu sunumu}

\author{
Mustafa Deniz Yörük ${ }^{1}$ P $\quad$ Pınar Tunçer ${ }^{2}$ Mevlüt Tuğrul Durmaz ${ }^{3}$ (D) \\ Zühre Aslı Aktan İkiz ${ }^{2}$ Okan Bilge ${ }^{2}$ Hülya Üçerler ${ }^{2}$ OD \\ ${ }^{1}$ Mugla Sıtkı Kocman University, Faculty of Medicine, Department of Anatomy, Mugla, Turkey \\ ${ }^{2}$ Ege University, Faculty of Medicine, Department of Anatomy, Izmir, Turkey \\ ${ }^{3}$ Antalya Education and Research Hospital, Department of Anesthesiology and Reanimation, Antalya, Turkey
}

\begin{abstract}
We report an abnormal origin of a vertebral artery (VA) on the left side of a 72-year-old male cadaver and refer to its clinical importance. In this cadaver, the left VA was originated from a common trunk with the left subclavian artery from the aortic arch. The significance of this arterial variety is crucial for surgery or invasive procedures at the base of the neck or trauma involving cervical structures.
\end{abstract}

Keywords: Vertebral artery, anatomical variation, subclavian artery, aortic arch, brachiocephalic trunk.

Öz

Bu çalışmada 72 yaşındaki erkek kadavrada sol arteria vertebralis (AV)'in anormal orijini gösterilmiş ve bu varyasyonun klinik önemine değinilmiştir. Bu kadavrada sol AV'nin, sol arteria subclavia ile birlikte, arcus aorta'dan çıkan ortak bir kökten orijin aldığı tespit edildi. Bu arteriyel varyasyonun boyun cerrahisi, invaziv kapalı girişimler ve boyun travmaları açısından önemli olduğunu düşünüyoruz.

Anahtar Sözcükler: Arteria vertebralis, anatomik varyasyon, arteria subclavia, arcus aorta, truncus brachiocephalicus.

\section{Introduction}

Classically, the VA arises from the superoposterior aspect of the first part of the subclavian artery as its first branch. It enters the transvers foramen in the transvers process of the 6th cervical vertebra and ascends through the foramina of the 6th to the 1st cervical vertebrae accompanied by a venous plexus and sympathetic nerves. It curves medially behind the lateral mass of atlas and lies in the groove on its posterior arch. It enters cranium via the foramen magnum (1-3). The VA provides the main arterial supply to the posterior fossa. Variations of VA are uncommon (4).
Based upon previously reported cases up to date, anomalous aortic arch origin of the VA is rarely seen on the right than the left (3-5). According to a review published in 1999, only nine cases were reported with right VA originating directly from the aortic arch (4). The left VA abnormal origin as presented in this case was detected more frequently.

\section{Case Report}

During a routine dissection period in Anatomy Department of Ege University Medicine Faculty, it was detected that a 72-year-old male cadaver had an anomalous origin of the left VA. It was originated from a common trunk of aortic arch with the left subclavian artery (Figure-1A).
Corresponding author: Mustafa Deniz Yörük

Mugla Sıtkı Kocman University, Faculty of Medicine,

Department of Anatomy, Mugla, Turkey

E-mail: md_yoruk@hotmail.com

Application date: 11.09.2019

Accepted: 01.11.2019 
The length of the common trunk was $8.0 \mathrm{~mm}$. The diameter of this trunk at the origin was 13.5 $\mathrm{mm}$. The diameters of left VA and left subclavian artery were $6.7 \mathrm{~mm}$ and $9.2 \mathrm{~mm}$ respectively. The left VA divided into two terminal branches $34.9 \mathrm{~mm}$ after its origin from the common trunk.

The left VA was wider and longer than the right VA in present cadaver. The right VA was originated from the right subclavian artery. The diameter of right VA was $5.2 \mathrm{~mm}$ at its origin and its length was $10.8 \mathrm{~mm}$ after thyrocervical trunk (Figure-1B). The diameter of right subclavian artery was $11.2 \mathrm{~mm}$ at its origin.

Additionally, the thyroid ima artery was arising from the aortic arch between the left common carotid artery and the brachiocephalic trunk (Figure-1A).

The diameter of aorta was $30.4 \mathrm{~mm}$ and the length of aortic arch was $40.1 \mathrm{~mm}$. There were no pathological conditions or signs concerning the neck and the mediastinal structures of the cadaver. The anatomical relationship of remaining vascular structures of the neck and upper thorax was normal. The study conforms to the provisions of the Helsinki Declaration of 1964 and all subsequent revisions.

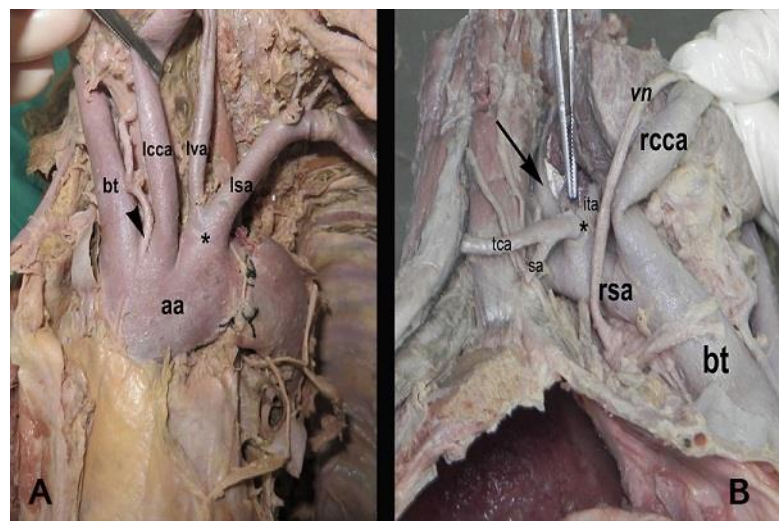

Figure-1. Abnormal origin of the VA on the left side. aa: aortic arch, bt: brachiocephalic trunk, Icca: left common carotid artery, Iva: left VA, Isa: left subclavian artery, arrowhead: thyroid ima artery, ": common trunk. B: The right VA was originated from the right subclavian artery. bt: brachiocephalic trunk, rsa: right subclavian artery, rcca: right common carotid artery, ita: inferior thyroid artery, sa: suprascapular artery, tca: transverse cervical artery, vn: vagal nerve, arrow: right $\mathrm{VA},{ }^{*}$ : right thyrocervical trunk.

\section{Discussion}

Karaköse et al. (6) also observed the same VA anomaly in two cadavers during anatomic dissections in 2006. The vertebral arteries originated directly from aortic arch. Both of cadavers had this anomaly on the left sides unilaterally as determined in present case.

Panicker et al. (7) also reported the left VA originated directly from the aortic arch. The inferior thyroid branch of thyrocervical trunk was absent on both sides in this case. They found the abnormal origin of the left VA in 1 of 20 cadavers $5 \%$. Daseler and Anson (8) determined same abnormal origin of the left VA in the range of about $1-3 \%$.

Yamaki et al. examined the vertebral arteries in 515 Japanese cadavers (3). Thirty of the 514 left vertebral arteries arose from aortic arch between the origins of left common carotid artery and the left subclavian artery. The frequency of a left VA arising from the aortic arch was $5.8 \%$ in that study.

Ottone et al. described two cases of left VA emerging from a trunk in common with left subclavian artery from the aortic arch (9). The anomaly in these two cases was the same with the anomaly described in present case.

Natsis et al. determined a combined anomalous origin of a left inferior thyroid artery and a left VA on a 72-year-old Caucasian male cadaver during a dissection anatomy practice. They reported that although many variations of the vertebral and inferior thyroid arteries were demonstrated in the literature, a combined variation of these two arteries was quite rare (2). The thyroid ima artery had a different origin in this present case.

For better understanding of this variation, it is important to know the embryological development of the aortic system. The first part of VA develops generally from proximal part of dorsal branch of seventh cervical intersegmental artery (7). It was described by the possibility that the left VA was formed by the connection of the 4th branchial artery to the superior wall of the aortic arch and not through the usual embryological process. They also observed that the left vertebral arteries that arose from the aortic arch had a high frequency of entrance at C3, C4 or C5 (3). The abnormal origin of the left VA from the aortic arch could be explained by a failure in the normal embryological process 
formed through the connection of the 4th aortic $\operatorname{arch}(9)$.

Akdeniz et al. reported that although most cases with anomalies of vertebral arteries were asymptomatic, some patients complained with symptoms of vertebro-basilar insufficiency (4).

Although the variations of the VA are uncommon, it has clinical importance to recognize the origin and course of the VA in the diagnostic procedures, catheter-based evaluation, cervicothoracic trauma that comprises the vascular structures and treatment of patients suffering from cerebrovascular disease $(4,5,7$, 9 ). The practitioners should keep in mind the possibility of the vascular anomalies. It is expected that the data and the review in this paper will be a guide to the clinicians during the surgical approaches or radiologic examinations of this region.

Conflict of interest: The authors have not declared any conflict of interest in this study.

\section{References}

1. Standring S (editor). Gray's anatomy: the anatomical basis of clinical practice. 39th ed. Edinburgh (Scotland): Elsevier Churchill Livingstone; 2005: 549.

2. Natsis K, Didagelos M, Noussios G, Adamopoulou A, Nikolaidou E, Paraskevas G. Combined anomalous origin of a left inferior thyroid artery and a left vertebral artery: a case report. Cases J. 2009; 26: 7400.

3. Yamaki K, Saga T, Hirata T et al. Anatomical study of the vertebral artery in Japanese adults. Anatomical Science International 2006; 81: 100-6.

4. Akdeniz B, Yilmaz E, Pekel N, Ergul BU. Anomalous origin of the right vertebral artery from the ascending aorta in the presence of an aberrant right subclavian artery. Int J Cardiovasc Imaging 2006; 23: 39-42.

5. Case D, Seinfeld J, Folzenlogen Z, Kumpe K. Anomalous right vertebral artery originating from the aortic arch distal to the left subclavian artery: a case report and review of the literature. J Vasc Interv Neurol. 2015; 8: 21-4.

6. Karaköse M, Gülekon N, Peker T, Anıl A, Turgut HB. Arcus aorta'dan çıkan arteria vertebralis varyasyonu: iki olgu sunumu. Gazi Medical Journal 2006; 17: 179-81.

7. Panicker HK, Tarnekar A, Dhawane V, Ghosh SK. Anomalous origin of left vertebral artery - embryological basis and applied aspects - a case report. J Anat Soc India 2002; 51: 234-5.

8. Daseler EH, Anson BJ. Surgical anatomy of the subclavian artery and its branches. Surg Gynecol Obstet.1959; 108: 149-74.

9. Ottone NE, Casola L, Cirigliano V et al. Two cases of left vertebral artery emerging from a trunk in common with the left subclavian artery from the aortic arch. Int. J. Morphol. 2013; 31: 646-9. 